\title{
Correction to: Nutrition behaviour and compliance with the Mediterranean diet pyramid recommendations: an Italian survey-based study
}

\author{
Renata Bracale ${ }^{1}$. Concetta M. Vaccaro ${ }^{2} \cdot$ Vittoria Coletta $^{2} \cdot$ Claudio Cricelli $^{3}$. Francesco Carlo Gamaleri ${ }^{4}$. \\ Fabio Parazzini ${ }^{5} \cdot$ Michele Carruba $^{6}$
}

Published online: 21 December 2019

(c) Springer Nature Switzerland AG 2019

\section{Correction to: \\ Eating and Weight Disorders - Studies on Anorexia, Bulimia and Obesity https://doi.org/10.1007/s40519-019-00807-4}

The article "Nutrition behaviour and compliance with the Mediterranean diet pyramid recommendations: an Italian survey-based study", written by "Renata Bracale, Concetta M. Vaccaro, Vittoria Coletta, Claudio Cricelli, Francesco Carlo Gamaleri, Fabio Parazzini and Michele Carruba" was originally published electronically on the publisher's internet portal on 8th November 2019 without open access. With the author(s)' decision to opt for Open Choice the copyright of the article changed on 23rd December 2019 to
(C) The Author(s) 2019 and the article is forthwith distributed under a Creative Commons Attribution 4.0 International License (https://creativecommons.org/licenses/by/4.0/), which permits use, sharing, adaptation, distribution and reproduction in any medium or format, as long as you give appropriate credit to the original author(s) and the source, provide a link to the Creative Commons licence, and indicate if changes were made.

The original article has been corrected.

Publisher's Note Springer Nature remains neutral with regard to jurisdictional claims in published maps and institutional affiliations.
The original article can be found online at https://doi.org/10.1007/ s40519-019-00807-4.

\section{Michele Carruba}

michele.carruba@unimi.it

1 Department of Medicine and Sciences for Health, Molise University, Campobasso, Italy

2 Fondazione Censis, Rome, Italy

3 Società Italiana di Medicina Generale e delle Cure Primarie Firenze, Florence, Italy

4 Ordine dei Farmacisti delle Province di Milano, Lodi e Monza Brianza, Milan, Italy

5 Dipartimento di scienze Cliniche e di Comunità, Università di Milano, Milan, Italy

6 Department of Medical Biotechnology and Translational Medicine, Center for the Study and Research on Obesity, University of Milan, Milan, Italy 